\title{
Madrid biocity: biomass and bioenergy potential
}

\author{
J.P. Paredes-Sánchez ${ }^{1}$ \\ ${ }^{1}$ Department of Energy \\ School of Mining, Energy and Materials Engineering of Oviedo \\ University of Oviedo \\ C/ Independencia 13, 33004 Oviedo (Spain). \\ Phone/Fax number: +0034 985 104305, e-mail: paredespablo@uniovi.es
}

\begin{abstract}
Fossil fuels such as oil, coal and natural gas represent the prime energy sources in the world. Large amounts of solid biomass are currently produced and used in the EU. Biomass energy is expected to make an important contribution to the energy and environmental objectives. Biocity is a new concept; it is a city that uses its own available biomass resources in a sustainable manner for energy purposes.
\end{abstract}

Based on BIORAISE GIS software for the assessment, an analysis of biomass and bioenergy were evaluated. This paper studies the available bioenergy to develop a stable biomass feedstock from the woodland and cropland residues for thermal purposes in a city. A case study is applied in Madrid. The result shows $228 \mathrm{dry} \mathrm{kt} / \mathrm{year}$ equivalent to 3,890 $\mathrm{TJ} /$ year as an energy resource.

\section{Key words}

Biomass, biocity, feedstock, residue.

\section{Introduction}

The EU believes that biomass for power and heat production can play a leading role by the year 2020 , when greenhouse gas emissions should have been reduced by $20 \%$, renewable energy sources should represent $20 \%$ of final energy consumption and energy efficiency should have increased by 20\% [1]. Emissions of anthropogenic origin, which mostly contribute to the greater concentration of $\mathrm{CO}_{2}$, come from using and consuming fossil fuels for domestic and industrial applications.

Biomass, like fossil fuels, releases $\mathrm{CO}_{2}$ when it is burned, but the $\mathrm{CO}_{2}$ released from biomass becomes part of a natural cycle. The important assumption behind this statement is that it must be constantly re-grown in order to store $C$ again. Biomass as an indigenous energy source, available in different areas, can diversify and ensure a secure energy supply [2]. It is a versatile combustible fuel as it can be directly profited from to produce electricity, heat or biofuels, being also a way of storing energy. It may be currently described as a clean, economicallycompetitive energy source having a maturely exploited technology [3]. However, it is a diverse and heterogeneous resource.

Potential biomass feedstocks include conventional crops and forestry products, agricultural residues, waste materials, and specially cultivated energy crops such as coppiced wood and perennial grasses. Feedstocks may also be produced domestically or imported.

For agricultural biomass, including energy crops, this simply means replanting crops once they have been harvested.

In the case of forest biomass, trees also have to be replanted, but the volumes harvested must never exceed the annual incremental growth.

Biomass, and the resulting useful forms of bioenergy produced from it, is anticipated by many advocates to provide a significant contribution to the primary energy supply in regions and cities.

Madrid is a south-western European city and the capital of Spain. The population of the city is about 3 million [4]. It is the third largest city and its metropolitan area is the third largest in the EU.

Energy and mining are leading industries. Madrid City Council is aware that climate change prevention and energy efficiency are among the main challenges facing the city of Madrid.

Biocity is a new concept; it is a city that uses its own available biomass resources in a sustainable manner for energy purposes to achieve sustainable development.

The major novelty of this study is the use of biomass to provide an assessment of the potential bioenergy derived from areas around cities.

The aim of this work is to evaluate the potential biomass and bioenergy to develop a stable biomass feedstock from the woodland and cropland residues for thermal purposes in Madrid. 


\section{Materials and methods}

The BIORAISE GIS software has been used in order to determine the types of available biomass. It is a GIS based tool specifically designed for the calculation of the biomass resources and costs existing around the selected locations.

In this study, the biomass resources considered have been those produced in the agricultural and forestry sector as consequence of field operations. Agricultural and forest field residues are considered to be produced in croplands and forests which have a null energy commercial demand. The amount total and available biomass resource is calculated from an average productivity value according to the corresponding ground uses in Corine Land Cover [5]. The biomasses are calculated by taking the collection area within the regional borders into consideration.

Regarding forest biomass, the analysis model of BIORAISE GIS is based on the use of the European cartography of the land uses Corine Land Cover and yield tables of relevant biomass species.

For agricultural biomass, the methodology uses data of agricultural surface and production data obtained from EUROSTAT [5].

For the calculation of the biomasses available, the area of a circle with centre point in Madrid city and a radius which is the maximum distance between this point and its regional border have been considered. The size of the city of Madrid allows the collection area to include the surrounding regional landscape. The collection point will be located in the centre point. Fig. 1 shows the collection area.

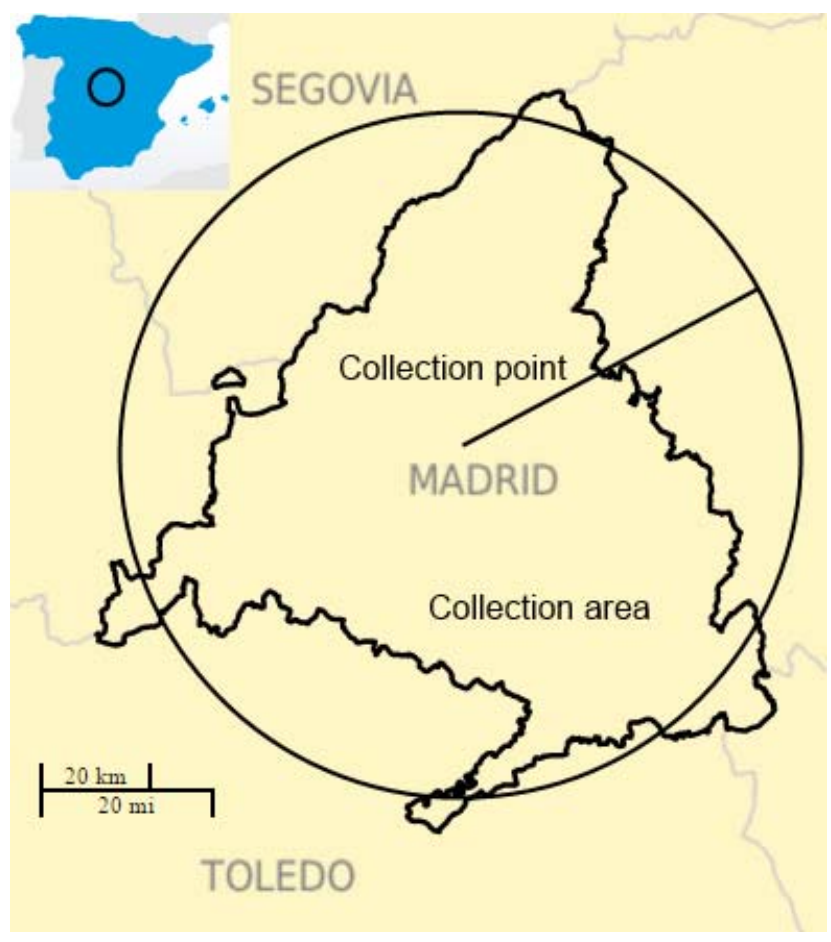

Fig. 1. Madrid collection area. Adapted from [6].
Available biomass is calculated from the total biomass introducing several techno-economical and environmental restrictions [7]. Techno-economical constrains derive from the harvesting methods based on operations and ground conditions to access to biomass in the collection area, because of environmental integrity limits the quantities of harvestable biomass.

Availability factor (w) is the relationship between the mass of available biomass ( $\mathrm{m}$ ) and the mass of total biomass (M) in the collection area under technoeconomical and environmental constrains; this is calculated from (1).

$$
\mathrm{m}=\mathrm{w} \cdot \mathrm{M}
$$

The " $\mathrm{m}$ " is the available mass, therefore accessible to be used as an energy resource under the constraints defined above; these resources are obtained from the total mass (M). The biomasses are evaluated on an oven dry mass basis (dry t).

The energy contained in biomass is restricted by the element composition. Higher and Lower Heating Values (HHV and LHV) are both used when calculating bioenergy potential. The two are different from each other depending on whether they contain heat from water vapor after burning or not [8]. Bioenergy GIS calculations can consider LHV referred to dry mass [9].

The bioenergy from the available biomass (E) is the result of multiplying the available mass by the Lower Heating Value (LHV) and is obtained from (2) [7].

$$
\mathrm{E}=\mathrm{m} \cdot \mathrm{LHV}
$$

Based on BIONLINE [6], maps of biomass were drawn to enable the detection of geographical areas with higher biomass quantities.

\section{Results}

Table I shows the available and total mass in the collection area.

\begin{tabular}{|c|c|c|}
\hline Type & $\begin{array}{c}\text { Available } \\
\text { Mass } \\
\text { (m) } \\
\text { (dry t/year) }\end{array}$ & $\begin{array}{c}\text { Total } \\
\text { Mass } \\
\text { (M) } \\
\text { (dry t/year) }\end{array}$ \\
\hline Rainfed & $93,022.81$ & $363,805.38$ \\
\hline Irrigated & $113,245.93$ & $141,456.50$ \\
\hline Vineyard & $1,986.75$ & $2,450.62$ \\
\hline Orchards & $1,447.50$ & $1,807.50$ \\
\hline Olive & $5,928.00$ & $7,465.25$ \\
\hline Meadow & $1,362.24$ & $12,626.25$ \\
\hline Broadleaves & $2,069.04$ & $35,104.69$ \\
\hline Conifers & $1,415.16$ & $9,236.86$ \\
\hline Mix conifers-broadleaves & 380.36 & $2,129.72$ \\
\hline Shrubs & $7,047.75$ & $42,300.00$ \\
\hline Total & $227,905.54$ & $618,382.77$ \\
\hline
\end{tabular}

Table I. - Biomass resources. 
There are differences between the total and the available mass for the different types of biomass. The total biomass is higher in rainfed and irrigated biomass resources.

Table II presents the availability factor in the collection area.

Table II. - Availability factor.

\begin{tabular}{|l|c|}
\hline \multicolumn{1}{|c|}{ Type } & $\begin{array}{c}\text { Availability } \\
\text { Factor } \\
\text { (w) }\end{array}$ \\
\hline Rainfed & 0.26 \\
\hline Irrigated & 0.80 \\
\hline Vineyard & 0.81 \\
\hline Orchards & 0.80 \\
\hline Olive & 0.79 \\
\hline Meadow & 0.11 \\
\hline Broadleaves & 0.06 \\
\hline Conifers & 0.15 \\
\hline Mix conifers-broadleaves & 0.18 \\
\hline Shrubs & 0.17 \\
\hline Total & 0.37 \\
\hline
\end{tabular}

The availability factor is higher in vineyard, irrigated and orchards. The highest availability factor and available biomass comes from the irrigated biomass.

Fig. 2 represents bioenergy distribution of agricultural crops around the city, where the largest share of these resources is located on the southern area of the city. This resource has an average value of 3 toe/ha year.

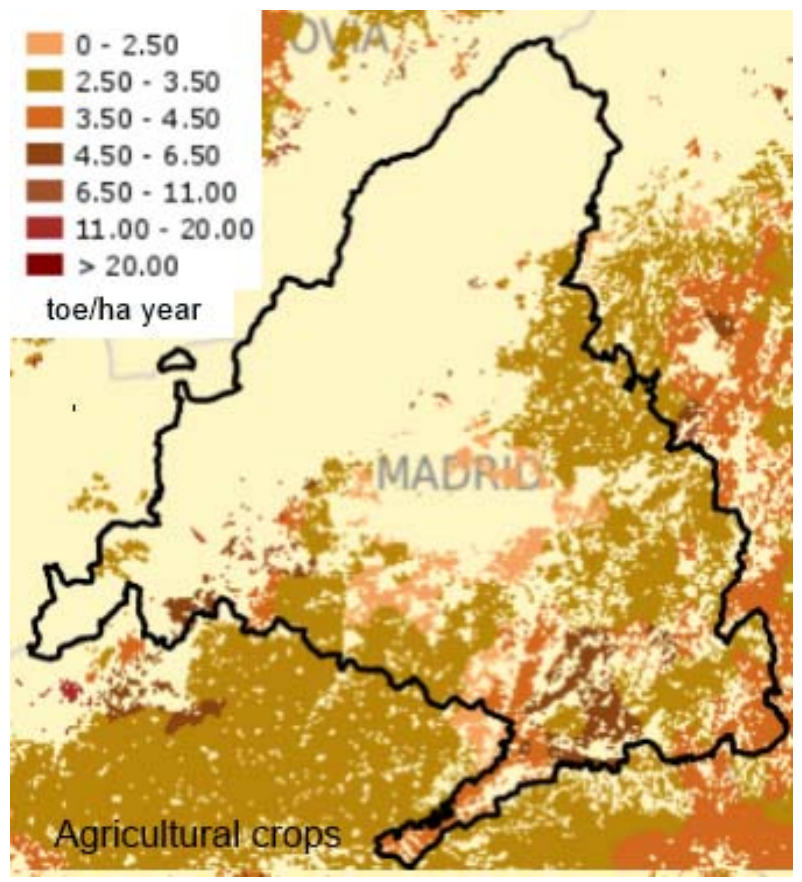

Fig. 2. Bioenergy distribution of agricultural crops in the collection area. Adapted from [6].

Fig. 3 shows bioenergy distribution of forest biomass in the collection area.

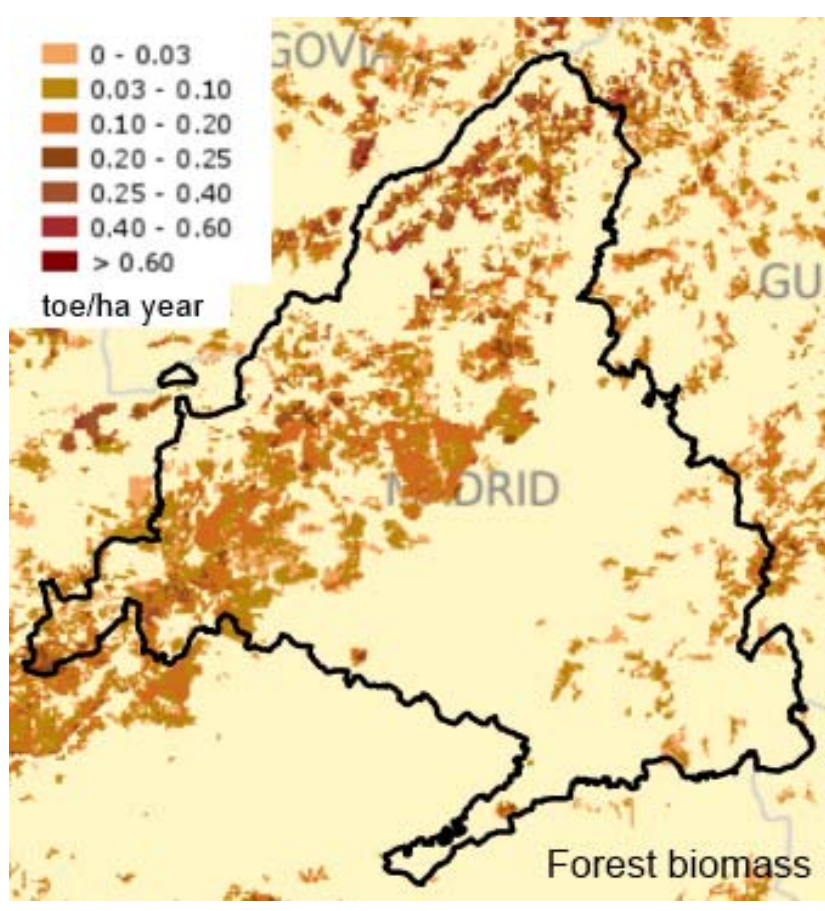

Fig. 3. Bioenergy distribution of forest biomass in the collection area. Adapted from [6].

The bioenergy distribution of forest biomass around the city is located on the northern area, about 0.2 toe/ha year. The use of the resources is strongly conditioned by their nature, technology infrastructure and energy market.

Table III indicates the available bioenergy in the collection area.

Table III. - Bioenergy distribution per biomass type.

\begin{tabular}{|l|c|}
\hline \multicolumn{1}{|c|}{ Type } & $\begin{array}{c}\text { Available } \\
\text { Energy } \\
\text { (E) } \\
\text { (GJ/year) }\end{array}$ \\
\hline Rainfed & $1,588,690.13$ \\
\hline Irrigated & $1,909,609.63$ \\
\hline Vineyard & $35,317.79$ \\
\hline Orchards & $24,775.49$ \\
\hline Olive & $105,992.64$ \\
\hline Meadow & $23,703.04$ \\
\hline Broadleaves & $36,500.00$ \\
\hline Conifers & $26,831.48$ \\
\hline Mix conifers-broadleaves & $6,960.81$ \\
\hline Shrubs & $131,546.25$ \\
\hline Total & $3,889,927.26$ \\
\hline
\end{tabular}

\section{Conclusion}

Sustainability especially concerns cities, where the population's future well-being is closely linked to a balance between the environment and urban development.

A city that uses its own available biomass resources in a sustainable manner defines a new concept, the biocity. 
In this work, a biocity methodology for biomass and bioenergy feedstock is presented.

The study carried out in Madrid (Spain) indicates that the total available biomass is $228 \mathrm{dry} \mathrm{kt} /$ year, equivalent to $3,890 \mathrm{TJ} /$ year, where the difference between the potential and the available biomass resources is higher in the agricultural activity than in the forestry one derived.

The biomass feedstock of households could be achieved through wise management of forests, that is to say, exploitation of residues from logging and agricultural crops. The average availability factor in the collection area is 0.37 , this biomass parameter is the result of dividing the available mass by the total mass.

The potential feedstock could turn Madrid into a biocity, where the theoretical available energy in the collection area is equivalent to the gas consumed by about 210,000 households in one year. However, this condition depends on the type of biomass, conversion technology and final energy application. The degree of exploitation of this potential depends on environment, infrastructure, technology and cost.

\section{Acknowledgement}

The author acknowledges the support of the Centre of Energy Research, Environment and Technology (CIEMAT) at the various stages of this work.

\section{References}

[1] H. Viana, W.B. Cohen, D. Lopes and J. Aranha. "Assessment of forest biomass for use as energy. GIS-based analysis of geographical availability and locations of woodfired power plants in Portugal”. Applied Energy, vol. 87, no8, pp. 2551-2560, 2010.

[2] C.D. Everard, K.P. McDonnell and C.C. Fagan. "Prediction of biomass gross calorific values using visible and near infrared spectroscopy”. Biomass and Bioenergy, vol. 45, pp. 203-211, 2012.

[3] R. Saidur, E.A. Abdelaziz, A. Demirbas, M.S. Hossain and S. Mekhilef. "A review on biomass as a fuel for boilers". Renewable and Sustainable Energy Reviews, vol. 15, n ${ }^{\circ}$, pp. 2262-2289, 2011.

[4] INE, Instituto Nacional de Estadística (2015). www.ine.es. Consulted: October 2015.

[5] BIORAISE, Biomass GIS data base (2015) http://bioraise.ciemat.es/bioraise. Consulted: October 2015.

[6] BIONLINE, Biomass GIS data base (2015). http://bionline.idae.es/biomasa/index.php?r=layers/gis. Consulted: October 2015.

[7] J.P. Paredes-Sánchez, A.J. Gutiérrez-Trashorras and J. Xiberta-Bernat. "Wood residue to energy from forests in the Central Metropolitan Area of Asturias (NW Spain)”. Urban Forestry \& Urban Greening, vol. 14, ${ }^{\circ}$ 2, pp. 195-199, 2015.

[8] H. Long, X. Li, H. Wang and J. Jia. "Biomass resources and their bioenergy potential estimation: A review". Renewable and Sustainable Energy Reviews, vol. 26, pp. 344-352, 2013.

[9] F. López-Rodríguez, C. Pérez Atanet, F. Cuadros Blázquez and A. Ruiz Celma. "Spatial assessment of the bioenergy potential of forest residues in the western province of Spain,
Caceres”. Biomass and Bioenergy, vol. 33, nº 10, pp. 13581366, 2009. 